\title{
Steady-State Analysis of ZVS and NON-ZVS Full- Bridge Inverters with Asymmetrical Control for Induction Heating Applications
}

\author{
Samart Yachiangkam*, Anawach Sangswang ${ }^{\dagger}$, Sumate Naetiladdanon*, \\ Chayant Koompai ${ }^{*}$, and Saichol Chudjuarjeen ${ }^{* *}$ \\ ${ }^{*}$ Department of Electrical Engineering, Faculty of Engineering, King Mongkut's University of \\ Technology Thonburi, Bangkok, Thailand \\ ${ }^{* *}$ Department of Electrical and Telecommunication Engineering, Faculty of Engineering, \\ Rajamangala University of Technology Krungthep, Bangkok, Thailand
}

\begin{abstract}
This paper presents a steady-state operation analysis of full-bridge series-resonant inverters focusing on the distorted load current due to low-quality-factor resonant circuits in induction heating and other applications. The regions of operation based on the zero-voltage switching (ZVS) and non-zero-voltage switching (NON-ZVS) operations of the asymmetrical voltage-cancellation control technique are identified. The effects of a distorted load current under a wide range of output powers are also analyzed for achieving a precise ZVS operating region. An experimental study is performed with a $1 \mathrm{~kW}$ prototype. Simulation and experimental studies have confirmed the validity of the proposed method. An efficiency comparison between the variable frequency method and the conventional fixed-frequency method is provided.
\end{abstract}

Key words: Asymmetrical voltage-cancellation, Induction heating, Non-zero- voltage switching, Series-resonant inverter, Zero-voltage switching

\section{INTRODUCTION}

High-frequency resonant inverters for induction heating (IH) technologies have been widely used in industrial, automotive, pipeline and consumer applications where high efficiency, system reliability, safety, cleanliness, compactness in volumetric physical size, light weight, and performance are required [1]. The use of a higher switching frequency results in higher switching losses, resulting in a lowered efficiency. However, this switching loss can greatly be reduced by the soft-switching technique [2]-[6]. The zero-voltage switching (ZVS) technique is one of the soft-switching techniques. It is the representative feature of resonant inverters and is suitable

Manuscript received Sep. 4, 2014; accepted Nov. 18, 2014

Recommended for publication by Associate Editor Yan Xing.

${ }^{\dagger}$ Corresponding Author: anawach.san@kmutt.ac.th

Tel: +662-470-9041, Fax: +662-470-9033, KMUTT

*Dept. of Electrical Eng., Faculty of Engineering, King Mongkut's University of Technology Thonburi, Thailand

** Dept. of Electrical and Telecommunication Eng., Faculty of Engineering, Rajamangala University of Technology Krungthep, Thailand for high-switching frequency operation. The ZVS operation avoids switching losses, reduces electromagnetic interference (EMI) and device stresses, and allows for the possibility of snubberless operation [4], [7]-[10]. Voltage-source resonant inverter topologies have received a great deal of attention because of their output power control capability under ZVS operation. Several switching techniques have been reported in high-frequency IH applications such as the pulse-frequency modulation (PFM) [11]-[13], pulse-density modulation (PDM) [14], [15], asymmetrical duty-cycle (ADC) [16], [17], phase-shift (PS) [18]-[20], and asymmetrical voltage-cancellation (AVC) [21]-[24]. In [24], the variable-frequency AVC control is used in a full-bridge resonant inverter with a low-quality-factor resonant circuit $\left(Q_{r}\right)$ to identify the condition of ZVS operation by the fundamental harmonic approximation technique. However, this technique may not guarantee ZVS operation in the entire range of output power. By using the AVC technique in the case of a low $Q_{r}$ resonant circuit (less than 2.5 [25]), the output current (load current) is non-sinusoidal due to a high damping factor $(\alpha)$ value. The 
transient response is oscillatory and exponentially damped in nature. The output current is unavoidably distorted and may result in hard-switching conditions during switching transitions at the end of the positive cycle, causing the so-called nonzero-voltage switching (NON-ZVS). Consequently, an increase in the switching losses and device stresses results in a lower efficiency.

In practice, the switching loss due to the effect of the parasitic capacitances associated with the charging and discharging of switching devices has been observed during a switching transition period. To mitigate this switching loss, the positive output current diverted from the resonant circuit should be large enough to completely discharge the parasitic capacitors and the switching frequency must be suitably increased above the resonant frequency.

The regions of ZVS and NON-ZVS operations of the full-bridge inverters for $\mathrm{IH}$ applications with a low $Q_{r}$ resonant circuit based on the asymmetrical control technique have been identified in this paper. The influence of parasitic capacitors are taken into consideration through computer simulations and verified by experimental results. The remainder of this paper consists of six sections. The circuit configurations and operations are described in Section II. Section III presents a steady state circuit analysis. In Section $\mathrm{IV}$, an analysis of the soft-switching operation is provided. The experimental setup and results are provided in Section V. Section VI concludes the work.

\section{CIRCUIT CONFIGURATION AND OPERATIONS}

\section{A. Circuit Configuration}

Fig. 1 shows a full-bridge series-resonant inverter circuit for induction heating applications. A voltage-source inverter consisting of four IGBTs $\left(S_{1}-S_{4}\right)$ with antiparallel diodes $\left(D_{1}-D_{4}\right)$ and parasitic capacitors $\left(C_{1}-C_{4}\right.$ or $\left.C_{o}\right)$, is connected with a series-resonant load. To eliminate the turn-on switching loss, all of the switches $\left(S_{1}-S_{4}\right)$ are operated at a frequency slightly higher than the resonant frequency under the ZVS condition.

\section{B. Steady-State ZVS Operation}

The gate signals for the switching devices $\left(S_{1}-S_{4}\right)$ and typical steady-state waveforms of the output voltage and current of the inverter for ZVS and NON-ZVS operations are shown in Fig. 2. As shown in Fig. 2(a), the inverter operates with the desired ZVS operation. Figs. 2(b) and (c) show steadystate waveforms for the NON-ZVS operations. The output power $P_{o}$ is adjusted by varying the shifted angle $\beta$ through switch $S_{4}$. The output voltage $v_{o}$ of the inverter assumes the form of a square wave while the output current $i_{o}$ is lagging the output voltage by the angle $\theta_{i o}$ at the end of the positive cycle of $i_{o} . \theta_{C o}$ is an angle defined at the completion of charging and discharging processes of $C_{1}$ and $C_{2}$, respectively. The fundamental components of the output voltage and

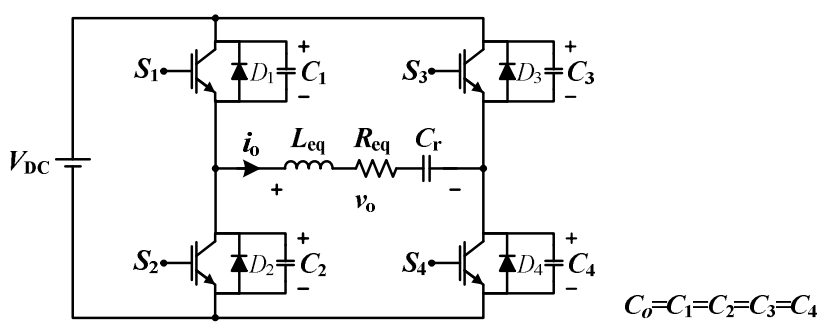

Fig. 1. Circuit configuration of full-bridge series-resonant inverter.

current are illustrated by the sinusoidal signals $V_{o 1}$ and $I_{o 1}$, respectively. The $I_{o 1}$ signal lags the $V_{o 1}$ signal by the phase angle $\theta_{z 1}$. The modes of operation with ZVS are described in eight stages $\left(t_{0}-t_{4}\right)$, as illustrated in Fig. 3 by the solid arrows.

Mode $1\left(\boldsymbol{t}_{\boldsymbol{0}}-\boldsymbol{t}^{\prime}{ }_{0}\right)$ : The switches $S_{2}$ and $S_{3}$ are already turned off, and the switches $S_{1}$ and $S_{4}$ are still off. Negative output current flows through the parasitic capacitors $C_{1}, C_{2}, C_{3}$ and $C_{4}$. The parasitic capacitors $C_{2}$ and $C_{3}$ are completely charged by the $L_{\mathrm{eq}}-C_{\mathrm{r}}$ resonant circuit while the parasitic capacitors $C_{1}$ and $C_{4}$ are completely discharged. At the same time, the output voltage increases from $-V_{\mathrm{DC}}$ to $+V_{\mathrm{DC}}$. From the Laplace transform, the output current $i_{o}$ and voltage $v_{o}$ during this mode are given as follows:

$\left.\begin{array}{l}i_{o}(t)=\left(\frac{A 1-R_{e q} I_{8}}{2 L_{e q} \omega_{d 1}}\right) e^{-\alpha t} \sin \omega_{d 1} t+I_{8} e^{-\alpha t} \cos \omega_{d 1} t \\ v_{o}(t)=\left[\begin{array}{l}\frac{\left(\alpha A 1-\left(\omega_{d 1}^{2}+\alpha^{2}\right) 2 L_{e q} I_{8}\right)\left(L_{e q} C_{r}\left(\omega_{d 1}^{2}+\alpha^{2}\right)-1\right)}{2 \omega_{d 1} L_{e q} C_{r}\left(\omega_{d 1}^{2}+\alpha^{2}\right)} e^{-\alpha t} \sin \omega_{d 1} t \\ +\frac{A 1\left(L_{e q} C_{r}\left(\omega_{d 1}^{2}+\alpha^{2}\right)-1\right)}{2 L_{e q} C_{r}\left(\omega_{d 1}^{2}+\alpha^{2}\right)} e^{-\alpha t} \cos \omega_{d 1} t+\frac{A 1}{2 L_{e q} C_{r}\left(\omega_{d 1}^{2}+\alpha^{2}\right)}\end{array}\right]+V_{0}\end{array}\right\}(1)$

where: $\quad \alpha=\frac{R_{e q}}{2 L_{e q}}, \omega_{d 1}=\sqrt{\frac{C_{r}+C_{o}}{L_{e q} C_{r} C_{o}}-\left(\frac{R_{e q}}{2 L_{e q}}\right)^{2}}, I_{8}=i_{o}\left(t_{4}\right)$ is the initial value of the output current $i_{o}$, and $A 1=$ $-2 V_{0}-V_{\mathrm{C} 1}+V_{\mathrm{C} 2}+V_{\mathrm{C} 3}-V_{\mathrm{C} 4}$ is the total initial voltage of the capacitor in each mode when $V_{0}$ is the initial voltage of the resonant capacitor $C_{r}$. $V_{\mathrm{C} 1}, V_{\mathrm{C} 2}, V_{\mathrm{C} 3}$, and $V_{\mathrm{C} 4}$ are the initial voltages of the parasitic capacitors $C_{1}, C_{2}, C_{3}$, and $C_{4}$, respectively.

Mode $2\left(t^{\prime}{ }_{0}-t_{1}\right)$ : At $t_{0}^{\prime}$, the switches $S_{2}$ and $S_{3}$ are still off. The negative output current is diverted from the parasitic capacitors $C_{1}$ and $C_{4}$ to the antiparallel diodes $D_{1}$ and $D_{4}$. Then it reaches zero at $t_{1}$. After the switch dead time $t_{d}$, the switches $S_{1}$ and $S_{4}$ receive positive gating signals and the output voltage is equal to $+V_{\mathrm{DC}}$. The current $i_{o}$ and voltage $v_{o}$ in this mode are expressed as:

$$
\left.\begin{array}{l}
i_{o}(t)=\left(\frac{A 2-R_{e q} I_{1}}{2 L_{e q} \omega_{d 2}}\right) e^{-\alpha t} \sin \omega_{d 2} t+I_{1} e^{-\alpha t} \cos \omega_{d 2} t \\
v_{o}(t)=\left[\begin{array}{l}
\frac{\left(\alpha A 2-\left(\omega_{d 2}^{2}+\alpha^{2}\right) 2 L_{e q} I_{1}\right)\left(L_{e q} C_{r}\left(\omega_{d 2}^{2}+\alpha^{2}\right)-1\right)}{2 \omega_{d 2} L_{e q} C_{r}\left(\omega_{d 2}^{2}+\alpha^{2}\right)} e^{-\alpha t} \sin \omega_{d 2} t \\
+\frac{A 2\left(L_{e q} C_{r}\left(\omega_{d 2}^{2}+\alpha^{2}\right)-1\right)}{2 L_{e q} C_{r}\left(\omega_{d 2}^{2}+\alpha^{2}\right)} e^{-\alpha t} \cos \omega_{d 2} t+\frac{A 2}{2 L_{e q} C_{r}\left(\omega_{d 2}^{2}+\alpha^{2}\right)}
\end{array}\right]+V_{0}
\end{array}\right\}(2)
$$




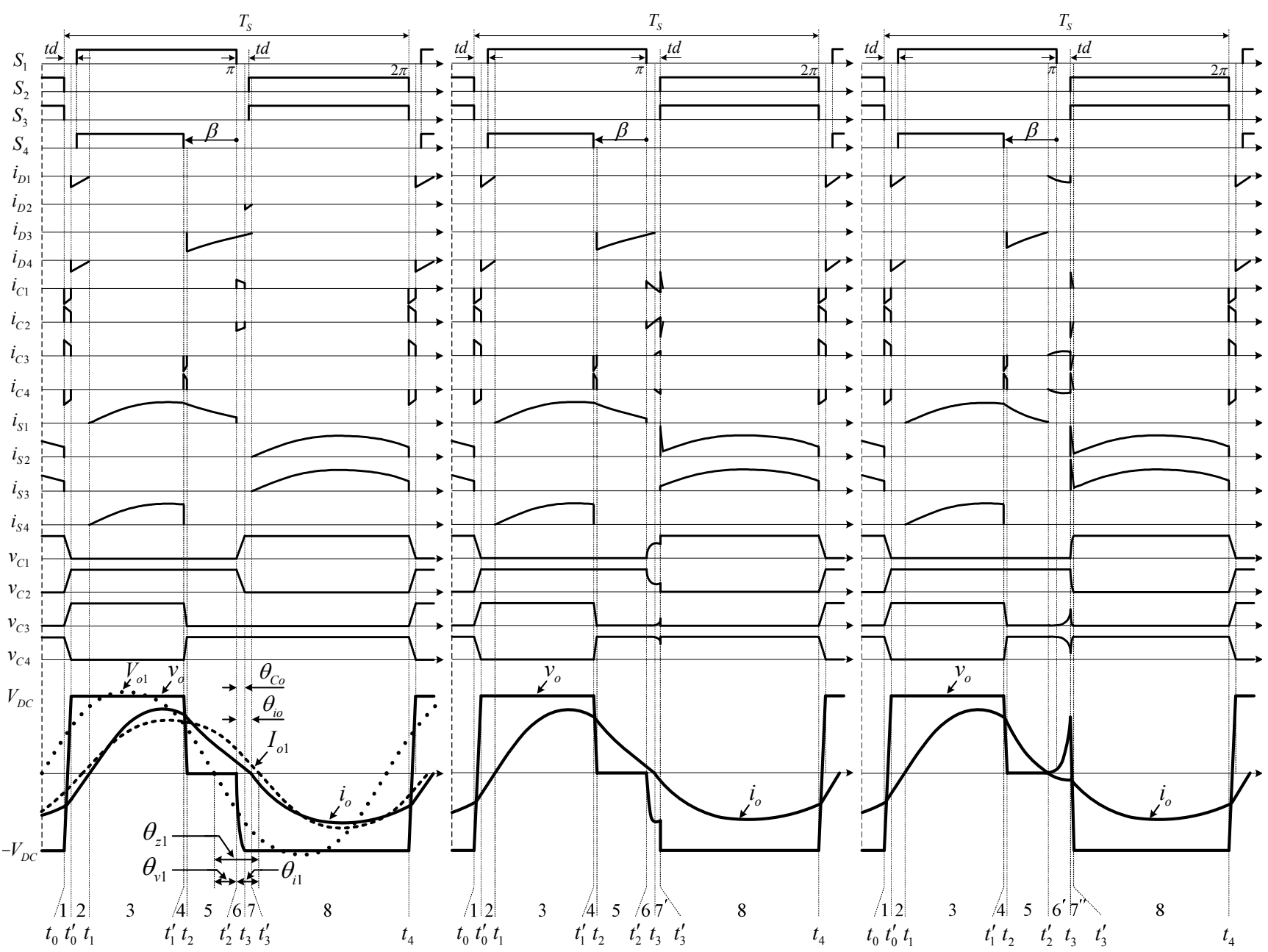

(a)

(b)

(c)

Fig. 2. The gate signals for all switches and typical steady-state waveforms of the output voltage and current. (a) Desired ZVS. (b) NON-ZVS I. (c) NON-ZVS II.

where: $\quad I_{1}=i_{o}\left(t_{0}^{\prime}\right), A 2=2\left(V_{D C}-V_{0}\right), \omega_{d 2}=\sqrt{\frac{1}{L_{e q} C_{r}}-\left(\frac{R_{e q}}{2 L_{e q}}\right)^{2}}$

Mode $3\left(t_{1}-t^{\prime}{ }_{1}\right)$ : At $t_{1}$, the switches $S_{1}$ and $S_{4}$ start conducting after the antiparallel diodes $D_{1}$ and $D_{4}$ are turned off, and the ZVS operation is obtained. The positive output current flows from zero until $t_{1}^{\prime}$, and the output voltage is still equal to $+V_{\mathrm{DC}}$. At this stage, the current $i_{o}$ and voltage $v_{o}$ in this mode are expressed as:

$i_{o}(t)=\left(\frac{A 3-R_{e q} I_{2}}{2 L_{e q} \omega_{d 3}}\right) e^{-\alpha t} \sin \omega_{d 3} t+I_{2} e^{-\alpha t} \cos \omega_{d 3} t$

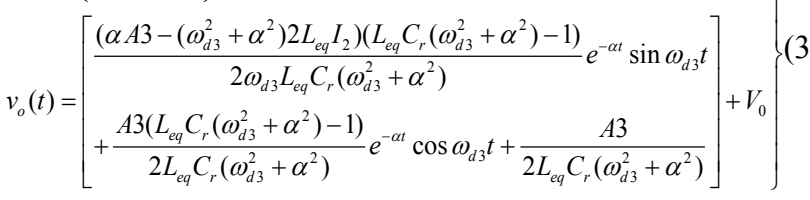

where: $I_{2}=i_{o}\left(t_{1}\right), A 3=2\left(V_{D C}-V_{0}\right), \omega_{d 3}=\sqrt{\frac{1}{L_{e q} C_{r}}-\left(\frac{R_{e q}}{2 L_{e q}}\right)^{2}}$

Mode $4\left(t^{\prime}{ }_{1}-t_{2}\right)$ : At $t_{1}^{\prime}$, while the switch $S_{1}$ still conducts, the switch $S_{4}$ is turned off due to the shifted angle $\beta$ that is adjusted to control the output power. During this mode, the output current flows in the same direction. The parasitic capacitor $C_{4}$ is charged while the parasitic capacitor $C_{3}$ is discharged. At this stage, the output voltage decreases to zero. The current $i_{o}$ and voltage $v_{o}$ are expressed as:

$i_{o}(t)=\left(\frac{A 4-R_{e q} I_{3}}{2 L_{e q} \omega_{d 4}}\right) e^{-\alpha t} \sin \omega_{d 4} t+I_{3} e^{-\alpha t} \cos \omega_{d 4} t$

$\left.v_{o}(t)=\left[\begin{array}{l}\frac{\left(\alpha A 4-\left(\omega_{d 4}^{2}+\alpha^{2}\right) 2 L_{e q} I_{3}\right)\left(L_{e q} C_{r}\left(\omega_{d 4}^{2}+\alpha^{2}\right)-1\right)}{2 \omega_{d 4} L_{e q} C_{r}\left(\omega_{d 4}^{2}+\alpha^{2}\right)} e^{-\alpha t} \sin \omega_{d 4} t \\ +\frac{A 4\left(L_{e q} C_{r}\left(\omega_{d 4}^{2}+\alpha^{2}\right)-1\right)}{2 L_{e q} C_{r}\left(\omega_{d 4}^{2}+\alpha^{2}\right)} e^{-\alpha t} \cos \omega_{d 4} t+\frac{A 4}{2 L_{e q} C_{r}\left(\omega_{d 4}^{2}+\alpha^{2}\right)}\end{array}\right]+V_{0}\right\}(4)$

where:

$I_{3}=i_{o}\left(t_{1}^{\prime}\right), A 4=V_{D C}-2 V_{0}+V_{C 3}-V_{C 4}, \omega_{d 4}=\sqrt{\frac{C_{r}+2 C_{o}}{2 L_{e q} C_{r} C_{o}}-\left(\frac{R_{e q}}{2 L_{e q}}\right)^{2}}$

Mode $5\left(t_{2}-t^{\prime}{ }_{2}\right)$ : At $t_{2}$, with a given value of the shifted angle $\beta$, the switch $S_{4}$ is already turned off while the switch $S_{1}$ still 


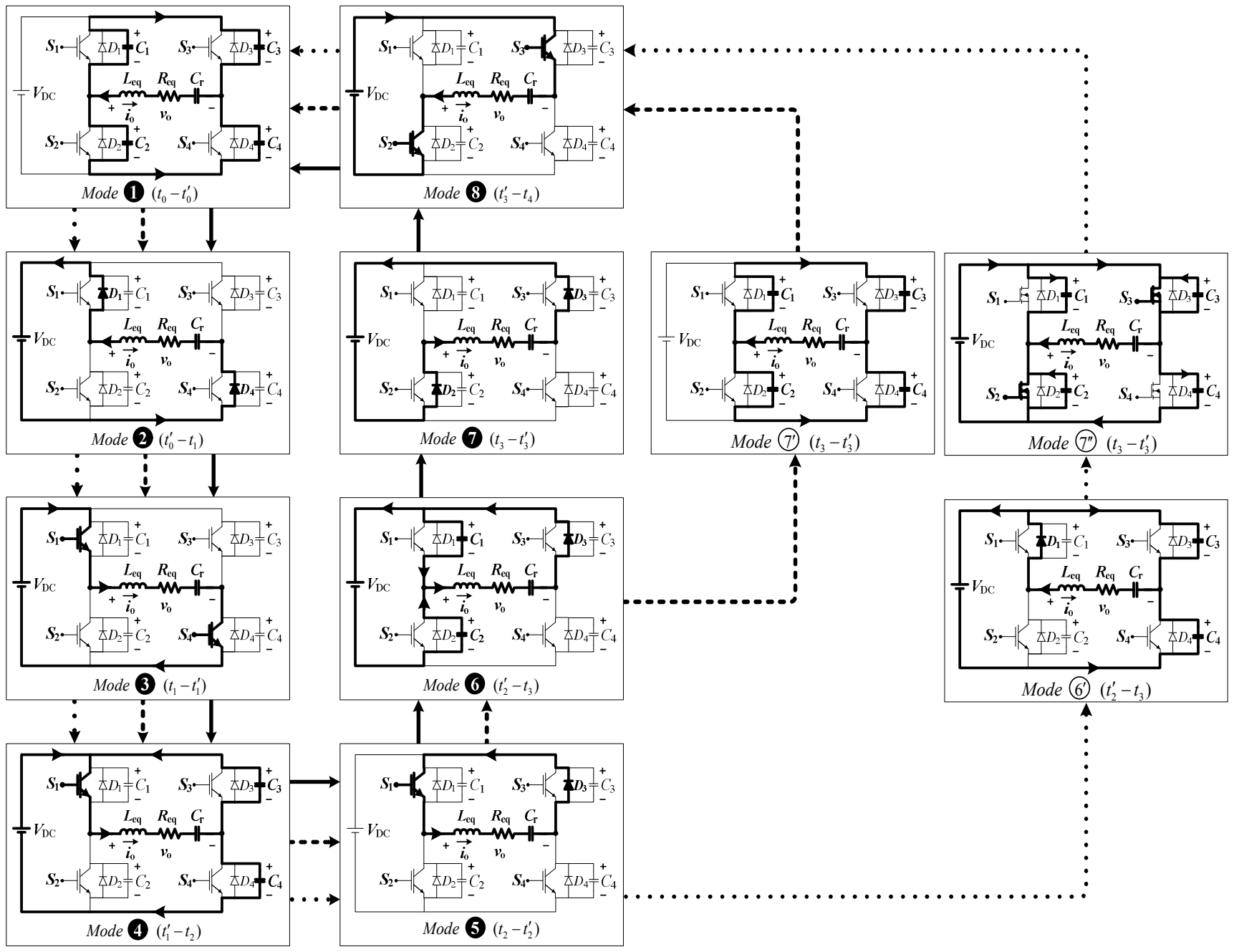

Fig. 3. Operation modes of a full-bridge resonant inverter: (a)

conducts and the output current flows through the antiparallel diode $D_{3}$. During this stage, the output voltage is already zero and the positive output current is decreasing. The current $i_{o}$ and voltage $v_{o}$ become:

$i_{o}(t)=\left(\frac{A 5-R_{e q} I_{4}}{2 L_{e q} \omega_{d 5}}\right) e^{-\alpha t} \sin \omega_{d 5} t+I_{4} e^{-\alpha t} \cos \omega_{d 5} t$

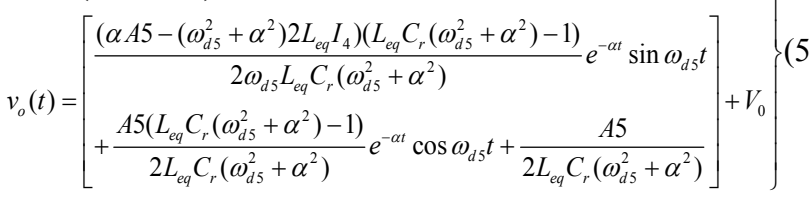

where: $I_{4}=i_{o}\left(t_{2}\right), A 5=-2 V_{0}, \omega_{d 5}=\sqrt{\frac{1}{L_{e q} C_{r}}-\left(\frac{R_{e q}}{2 L_{e q}}\right)^{2}}$

Mode $6\left(t^{\prime}{ }_{2}-t_{3}\right)$ : At $t_{2}^{\prime}$, all of the switches are off. A part of the positive output current flows through the antiparallel diode $D_{3}$ and the parasitic capacitors $C_{1}$ and $C_{2}$. At the same time, the capacitor voltage $V_{\mathrm{C} 1}$ increases from zero to $+V_{\mathrm{DC}}$, whereas the capacitor voltage $V_{\mathrm{C} 2}$ decreases from $+V_{\mathrm{DC}}$ to zero. In this mode, the output voltage reduces from zero to $-V_{\mathrm{DC}}$ at $t_{3}$. The current $i_{o}$ and voltage $v_{o}$ are:

$$
\left.\begin{array}{l}
i_{o}(t)=\left(\frac{A 6-R_{e q} I_{5}}{2 L_{e q} \omega_{d 6}}\right) e^{-\alpha t} \sin \omega_{d 6} t+I_{5} e^{-\alpha t} \cos \omega_{d 6} t \\
v_{o}(t)=\left[\begin{array}{l}
\frac{\left(\alpha A 6-\left(\omega_{d 6}^{2}+\alpha^{2}\right) 2 L_{e q} I_{5}\right)\left(L_{e q} C_{r}\left(\omega_{d 6}^{2}+\alpha^{2}\right)-1\right)}{2 \omega_{d 6} L_{e q} C_{r}\left(\omega_{d 6}^{2}+\alpha^{2}\right)} e^{-\alpha t} \sin \omega_{d 6} t \\
+\frac{A 6\left(L_{e q} C_{r}\left(\omega_{d 6}^{2}+\alpha^{2}\right)-1\right)}{2 L_{e q} C_{r}\left(\omega_{d 6}^{2}+\alpha^{2}\right)} e^{-\alpha t} \cos \omega_{d 6} t+\frac{A 6}{2 L_{e q} C_{r}\left(\omega_{d 6}^{2}+\alpha^{2}\right)}
\end{array}\right]+V_{0}
\end{array}\right\}
$$

where:

$$
I_{5}=i_{o}\left(t_{2}^{\prime}\right), A 6=-V_{D C}-2 V_{0}+V_{C 1}-V_{C 2}, \omega_{d 6}=\sqrt{\frac{C_{r}+2 C_{o}}{2 L_{e q} C_{r} C_{o}}-\left(\frac{R_{e q}}{2 L_{e q}}\right)^{2}}
$$

Mode $7\left(t_{3}-t^{\prime}{ }_{3}\right)$ : At $t_{3}$, the switch $S_{1}$ is still off during the dead time. The antiparallel diodes $D_{2}$ and $D_{3}$ naturally conduct while the positive output current decreases to zero at $t_{3}^{\prime}$. At this stage, the output voltage is equal to $-V_{\mathrm{DC}}$. The switches $S_{2}$ and $S_{3}$ receive the same positive gating signal. Therefore, the current $i_{o}$ and voltage $v_{o}$ in this mode are: 
$i_{o}(t)=\left(\frac{A 7-R_{e q} I_{6}}{2 L_{e q} \omega_{d 7}}\right) e^{-\alpha t} \sin \omega_{d 7} t+I_{6} e^{-\alpha t} \cos \omega_{d 7} t$

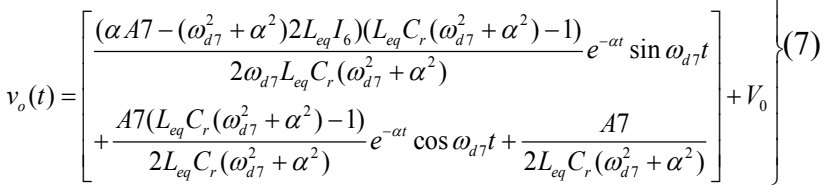

where: $I_{6}=i_{o}\left(t_{3}\right), A 7=-2\left(V_{D C}-V_{0}\right), \omega_{d 7}=\sqrt{\frac{1}{L_{e q} C_{r}}-\left(\frac{R_{e q}}{2 L_{e q}}\right)^{2}}$

Mode $8\left(\boldsymbol{t}^{\prime}{ }_{3}-t_{4}\right)$ : At $t_{3}^{\prime}$, as soon as the antiparallel diodes $D_{2}$ and $D_{3}$ are turned off, the switches $S_{2}$ and $S_{3}$ conduct under ZVS operation. During this stage, the output current and voltage are both negative and a full cycle of waveform is achieved. This can be expressed by:

$\left.\begin{array}{l}i_{o}(t)=\left(\frac{A 8-R_{e q} I_{7}}{2 L_{e q} \omega_{d 8}}\right) e^{-\alpha t} \sin \omega_{d 8} t+I_{7} e^{-\alpha t} \cos \omega_{d 8} t \\ v_{o}(t)=\left[\begin{array}{l}\frac{\left(\alpha A 8-\left(\omega_{d 8}^{2}+\alpha^{2}\right) 2 L_{e q} I_{7}\right)\left(L_{e q} C_{r}\left(\omega_{d 8}^{2}+\alpha^{2}\right)-1\right)}{2 \omega_{d 8} L_{e q} C_{r}\left(\omega_{d 8}^{2}+\alpha^{2}\right)} e^{-\alpha t} \sin \omega_{d 8} t \\ +\frac{A 8\left(L_{e q} C_{r}\left(\omega_{d 8}^{2}+\alpha^{2}\right)-1\right)}{2 L_{e q} C_{r}\left(\omega_{d 8}^{2}+\alpha^{2}\right)} e^{-\alpha t} \cos \omega_{d 8} t+\frac{A 8}{2 L_{e q} C_{r}\left(\omega_{d 8}^{2}+\alpha^{2}\right)}\end{array}\right]+V_{0}\end{array}\right\}(8)$

where: $I_{7}=i_{o}\left(t_{3}^{\prime}\right), A 8=-2\left(V_{D C}-V_{0}\right), \omega_{d 8}=\sqrt{\frac{1}{L_{e q} C_{r}}-\left(\frac{R_{e q}}{2 L_{e q}}\right)^{2}}$

\section{NON-ZVS Operation}

Two NON-ZVS operations have been observed as illustrated in Fig. 3. The first one emanated from an increase in the shifted angle $\beta$ with the aim of reducing the output power without varying the switching frequency $f_{s}$. The first category of NON-ZVS operations (NON-ZVS $I$ ) is indicated by the dashed arrows where the previously described operation of mode 7 is replaced by mode $7^{\prime}$. Mode 6 begins after the gate signal of $S_{1}$ is removed at $t_{2}^{\prime}$, as depicted in Fig. 2(b). The positive output current flows through the circuit formed by $C_{1}$, $C_{2}, D_{3}$, and the DC input voltage source. During this interval, the capacitor voltage $V_{\mathrm{C} 1}$ increases whereas the capacitor voltage $V_{\mathrm{C} 2}$ decreases. The output voltage becomes negative in this mode. At the beginning of mode $7^{\prime}$, after the antiparallel diode $D_{3}$ is turned off at $t_{3}$ with no gate signals of $S_{2}$ and $S_{3}$, the output current becomes negative and flows through the parasitic capacitors $C_{1}, C_{2}, C_{3}$ and $C_{4}$. Therefore, the voltages across the switches $S_{2}$ and $S_{3}$ increase. At $t_{3}^{\prime}$, the switches $S_{2}$ and $S_{3}$ start conducting under the NON-ZVS. The parasitic capacitors $C_{1}$ and $C_{2}$ experience an instantaneous voltage change. This results in high current spikes in the switches $S_{1}$ and $S_{2}$. In this case, the modes of operation are sequenced as $1023060(7)$

The second category of NON-ZVS operations (NON-ZVS II) is indicated by the dotted arrows in Fig. 3. It can also be divided into eight stages as (1) 2 (3) 5 (6) (7) 8 . The original operations of modes 6 and 7 in the ZVS operation are changed to modes $6^{\prime}$ and $7^{\prime \prime}$, respectively. The operation in mode $6^{\prime}$ begins when the positive output current becomes zero at $t_{2}^{\prime}$ before the end of the gate signal of $S_{1}$, depicted in Fig. 2(c). The negative output current flows through the antiparallel diode $D_{1}$ and the parasitic capacitors $C_{3}$ and $C_{4}$. During this mode, the capacitor voltage $V_{\mathrm{C} 3}$ increases whereas the capacitor voltage $V_{\mathrm{C} 4}$ decreases, adding up to a high value for the output voltage depending on the operating frequency. At the same time, the capacitor voltages $V_{\mathrm{C} 1}$ and $V_{\mathrm{C} 2}$ remain unchanged at zero and $+V_{\mathrm{DC}}$, respectively. Mode 7" begins at $t_{3}$. The switches $S_{2}$ and $S_{3}$ start conducting instantaneously under the NON-ZVS operation. Since the capacitor voltage $V_{\mathrm{C} 1}$ is initially zero, this creates a short-circuit path of the input voltage source through the switch $S_{2}$. All of the parasitic capacitors suffer from a sudden voltage change that results in current spikes in the capacitors $\left(C_{1}-C_{4}\right)$ and the switches $S_{2}$ and $S_{3}$ for a short interval. Such an operation reduces the inverter efficiency due to the high turn-on switching loss and it causes device stress, which may destroy all of the switches.

Therefore, for the case of a low $Q_{r}$ resonant circuit, the damping frequency $\omega_{d}$ of the series-resonant circuit is less than the resonant angular frequency $\omega_{r}$ due to a high damping factor $\alpha$. Two NON-ZVS operations on the switches $S_{2}$ and $S_{3}$ are likely to be encountered if the inverter is operated at an unsuitable switching frequency.

\section{Steady State Circuit Analysis}

The induction heating load can be modeled as an equivalent resistor $\left(R_{e q}\right)$ and inductor $\left(L_{e q}\right)$. The resonant circuit is formed by adding a resonant capacitor $\left(C_{r}\right)$, as shown in Fig. 1. The load quality factor of the resonant circuit is defined as:

$$
Q_{r}=\frac{2 \pi f_{r} L_{e q}}{R_{e q}}=\frac{1}{2 \pi f_{r} R_{e q} C_{r}}
$$

where $f_{r}$ is the resonant frequency, and $f_{r}=1 / 2 \pi \sqrt{L_{e q} C_{r}}$.

A steady-state analysis of the series-resonant circuit is based on the equivalent parameters and typical waveforms under the ZVS operation as shown in Fig. 1 and Fig. 2(a), respectively. To simplify the analysis, the conventional assumptions are made for the analysis in this section as follows.

1) The converter elements are ideal.

2) The effect of the ripples from the DC input voltage is neglected.

3) The parasitic inductance and capacitance in the switches are neglected.

With the stated assumption, the magnitude of the impedance $\hat{Z}_{e q}$ of the series-resonant circuit can be obtained as: 


$$
\hat{Z}_{e q}=R_{e q} \sqrt{1+Q_{r}^{2}\left(h f_{n}-\frac{1}{h f_{n}}\right)^{2}}
$$

where $h$ is the order of harmonic components, and $f_{n}$ is the normalized frequency $\left(f_{s} / f_{r}\right)$.

The impedance phase angle of the harmonic components is given by:

$$
\theta_{z h}=\tan ^{-1}\left[Q_{r}\left(h f_{n}-\frac{1}{h f_{n}}\right)\right]
$$

The output voltage is given by:

$$
v_{o}(t)=\sum_{h=0}^{\infty} \hat{V}_{o h} \sin \left(h \omega t+\theta_{v h}\right)
$$

The amplitude of the harmonic components of the output voltage can be written by means of the Fourier series as:

$$
\hat{V}_{o h}= \begin{cases}\frac{V_{D C}}{h \pi} \sqrt{10+6 \cos h \beta} & ; h=1,3,5,7, \ldots \\ \frac{V_{D C}}{h \pi} \sqrt{2-2 \cos h \beta} & ; h=2,4,6,8, \ldots\end{cases}
$$

where $\beta$ is the shifted angle of the switch $S_{4}$ with a value from $0^{\circ}$ to $180^{\circ}$, and $V_{D C}$ is the DC bus voltage. The angle $\theta_{v h}$ between the output voltage $v_{o}$ and its harmonic voltage $\left(V_{o h}\right)$ can be determined by:

$$
\theta_{v h}= \begin{cases}\tan ^{-1} \frac{\sin h \beta}{3+\cos h \beta} & ; h=1,3,5,7, \ldots \\ \tan ^{-1} \frac{\sin h \beta}{\cos h \beta-1} & ; h=2,4,6,8, \ldots\end{cases}
$$

The output current can also be written by:

$$
i_{o}(t)=\sum_{h=0}^{\infty} \hat{I}_{o h} \sin \left(h \omega t-\theta_{i h}\right)
$$

where the angle $\theta_{i h}$ is the phase difference between the output voltage and the impedance phase angle $\left(\theta_{i h}=\theta_{v h}-\theta_{z h}\right)$. The amplitude of the harmonic components of the output current is given by:

$$
\hat{I}_{o h}=\frac{\hat{V}_{o h}}{R_{e q} \sqrt{1+Q_{r}^{2}\left(h f_{n}-\frac{1}{h f_{n}}\right)^{2}}}
$$

Note that if the load quality factor is sufficiently high (more than 2.5), the output current $i_{o}$ flowing through the series-resonant circuit assumes the form of a sinusoidal wave. In addition, the angle $\theta_{i o}$ in Fig. 2(a) can be reasonably approximated by the phase difference $\theta_{i 1}$.

From (16), the average output power $P_{o}$ is given as:

$$
P_{o} \simeq \sum_{h=0}^{\infty} I_{o h, r m s}^{2} \cdot R_{e q} \simeq \sum_{h=0}^{\infty} \frac{\hat{V}_{o h}^{2}}{2 R_{e q}\left(1+Q_{r}^{2}\left(h f_{n}-\frac{1}{h f_{n}}\right)^{2}\right)}
$$

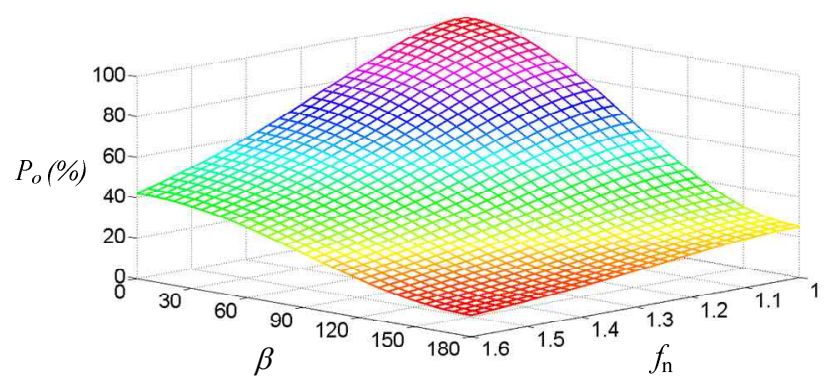

Fig. 4. The relationship of percent output power, $\beta$, and $f_{n}$.

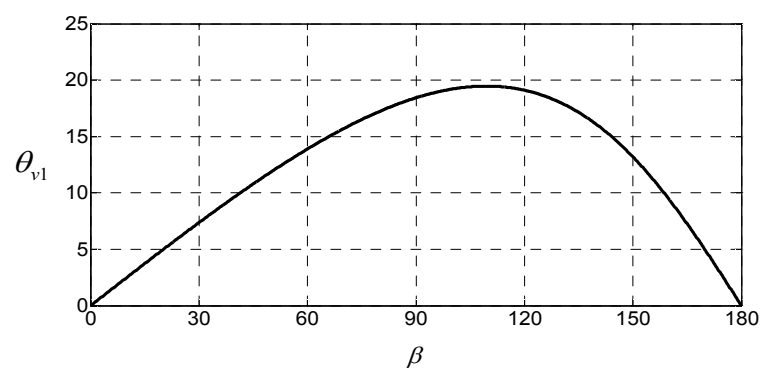

Fig. 5. The angle $\theta_{v 1}$ as a function of shifted angle $\beta$.

The maximum value of the output power in (17) occurs at $f_{n}$ $=1$ and $\beta=0$. Clearly, if the normalized frequency $f_{n}$ and $\beta$ are increased, the output power is reduced, as shown in Fig. 4 (i.e., an increase of $\beta$ will result in a reduction of the output power). However, the minimum output power is limited to $25 \%$ of the maximum output power at $\beta=180^{\circ}$ since the output voltage control is through an adjustment of the positive cycle and the minimum achievable output voltage is at $50 \%$ of its rated value [21].

\section{ANALYSIS OF THE SOFT-SWITCHING OPERATION}

A necessary requirement for the ZVS operation of a fullbridge resonant inverter with the asymmetrical voltage-cancellation control technique is that the applied voltage across the switches must be zero during the turn-on operation. Although, the switching frequency of the series-resonant inverter is higher than the resonant frequency, the NON-ZVS operations may occur due to an increase in the shifted angle $\beta$, resulting in a variation of the angle $\theta_{v 1}$, as shown in Fig. 5. From Fig. 2(a), neglecting the parasitic capacitances, the ZVS condition requires that the angle $\theta_{i o}$ must be greater than zero. This means that the positive output current waveforms become zero after the end of the gate signal $S_{1}$ (i.e., the antiparallel diodes $D_{2}$ and $D_{3}$ provide a path for the energy stored in the resonant circuit that must be conducted at $t_{2}^{\prime}$ ).

In practice, the inverter is operated at high frequencies and the effects of the parasitic capacitors can be significant. They can alter the predetermined ZVS operation during a switching transition at the end of the positive cycle of $i_{o}$. The discharging processes of the parasitic capacitor $C_{2}$ must be 


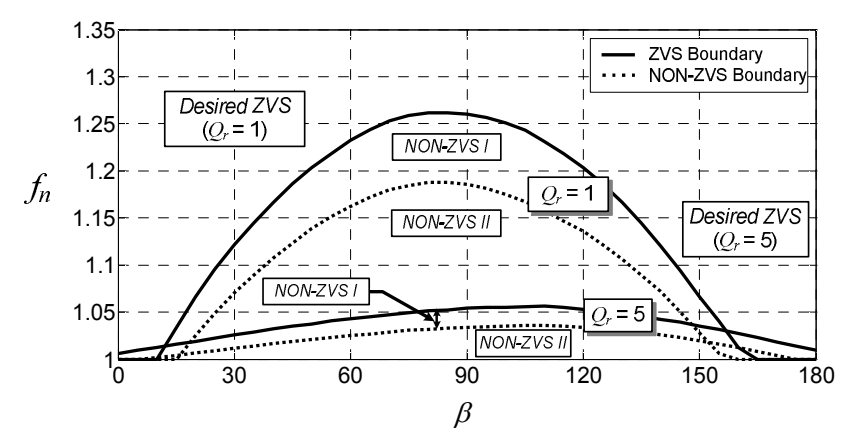

Fig. 6. Regions of ZVS and NON-ZVS operations in terms of $f_{n}$.

complete before the output current reaches zero (i.e., the output current should be large enough to ensure the ZVS condition). Therefore, the output current continues to flow through the antiparallel diodes $D_{2}$ and $D_{3}$. The critical angle of the parasitic capacitors is calculated by:

$$
\theta_{C o, c r i}=\frac{4 \pi f_{s} C_{o} V_{D C}}{\left.i_{o}(t)\right|_{t=\pi}}
$$

where $C_{o}$ is the parasitic capacitor of the switch, and $\left.i_{o}(t)\right|_{t=\pi}$ is the output current at $180^{\circ}$.

The angle $\theta_{C o, c r i}$ may be used to define a proper dead time interval. The critical ZVS boundary of operation is obtained by setting $\theta_{i o}=\theta_{C o, c r i}=\theta_{t d}$ in (15) where $\theta_{t d}$ is an angle of the dead time $t_{d}$. The critical ZVS boundary under the effect of $C_{o}$ is obtained as indicated by the solid line while neglecting $C_{o}$ as indicated by the dotted line in Fig. 6. If the load quality factor is high, for example $Q_{r}=5$, the boundary line is rather flat with $f_{n}$ around 1.06 at $110^{\circ}$ of the shifted angle $\beta$. On the other hand, at $Q_{r}=1$, the highest boundary value of $f_{n}$ will shift to around $80^{\circ}$ of the shifted angle $\beta$. Therefore, the regions of ZVS and the two NON-ZVS operations can be identified in terms of $f_{n}$ as described in Section II. Again, the dotted line is the boundary between the NON-ZVS $I$ and the NON-ZVS II operations (where $\theta_{i o}=0$ ) whereas the solid line is the boundary between the desired ZVS and the NON-ZVS $I$ operations. This implies that a switching frequency higher than the solid line will ensure the ZVS operation. If the shifted angle $\beta$ is adjusted to $60^{\circ}, f_{n}$ must be more than 1.24 to guarantee the ZVS operation. In addition, the conventional AVC control with fixed frequency control requires the inverter to operate above the resonant frequency (i.e. $f_{s}>f_{r}$ ) and the highest boundary value of $f_{n}$, specifically $f_{n}>1.26$ for this case, at all times.

\section{EXPERIMENTAL SETUP AND RESULTS}

\section{A. Experimental Setup}

A hardware prototype is created where an induction cooker is used to illustrate the proposed analysis on the low $Q_{r}$ resonant circuit. The system controller is an STM32F4
TABLE I

INVERTER SPECIFICATIONS AND CIRCUIT PARAMETERS

\begin{tabular}{ccc}
\hline Symbol & Quantity & Value \\
\hline$V_{\mathrm{DC}}$ & DC input voltage & $135 \mathrm{~V}$ \\
$f_{r}$ & Resonant frequency & $33 \mathrm{kHz}$ \\
$f_{s}$ & Switching frequency & $33.75-45.5 \mathrm{kHz}$ \\
$C_{r}$ & Resonant capacitance & $300 \mathrm{nF}$ \\
$L_{e q}$ & Equivalent inductance & $77 \mu \mathrm{H}$ \\
$R_{e q}$ & Equivalent resistance & $14 \Omega$ \\
$S_{1}-S_{4}$ & Switches & IRG4PC50UD \\
\hline
\end{tabular}

discovery board. To avoid acoustic noise from the induction coil and the cooking vessel, the resonant frequency must be over $20 \mathrm{kHz}$. The material used in the cooking vessel is essential in terms of efficiency. The cooking vessel is an off-the-shelf low-cost vessel made of stainless steel that measures $235 \mathrm{~mm}$ in diameter and $75 \mathrm{~mm}$ in height. The bottom and wall thicknesses are $1.4 \mathrm{~mm}$ and $0.8 \mathrm{~mm}$, respectively.

The induction coil is a 29-turn flat spiral made of a litz wire consisting of 35 strands of 26 SWG wire to reduce the skin effect losses and the consequent increase of heat in the coil. The maximum coil current is approximately $12 \mathrm{~A} \mathrm{rms.} \mathrm{A}$ resonant capacitor $C_{r}$ of $300 \mathrm{nF}, 1000 \mathrm{~V}$ has been selected to provide the resonant frequency at $33 \mathrm{kHz}$, and the quality factor $Q_{r}$ at resonance is approximately one. Note that the resonant capacitor needs to withstand the peak voltage, which may be greater than the DC input voltage because of voltage magnification due to the circuit quality factor.

The inverter specifications and circuit parameters are given in Table I. The dead time interval $t_{d}$ is chosen as $320 \mathrm{~ns}$ based on the manufacturer's data sheet. For the complete ZVS condition, the angle $\theta_{i o}$ must be higher than the angle $\theta_{t d}$, as shown in Fig. 2(a). As mentioned before, an increase of the shifted angle $\beta$ will cause a reduction of the angle $\theta_{i o}$. In this experiment, the angle $\theta_{i o}$ is set at $7^{\circ}$ by controlling the switching frequency. In the worst case scenario, where the shifted angle $\beta$ is around $80^{\circ}$, the switching frequency must increase to $45.5 \mathrm{kHz}\left(f_{n}=1.37\right)$ so that the angle $\theta_{i o}$ becomes $7^{\circ}$ (425 ns). Thus, the switching frequency of the inverter is varied between $33.75 \mathrm{kHz}$ and $45.5 \mathrm{kHz}$ to assure operation in the desired ZVS region as shown in Fig. 6.

\section{B. Simulation and Experimental Results}

A computer simulation is performed to illustrate the proposed boundaries of the ZVS and NON-ZVS operations using the inverter specifications and circuit parameters from Table I. To demonstrate the inverter operation in the ZVS, critical ZVS, NON-ZVS I, and NON-ZVS II regions, the corresponding switching frequencies are set to 45.5, 40.5, 39.5 and $36 \mathrm{kHz}$, respectively. In addition, the shifted angle $\beta$ is initially set at $80^{\circ}$.

The steady-state phase plane trajectories of the current and voltage of the inverter $\left(i_{o}\right.$ and $\left.v_{o}\right)$ and the switches $\left(i_{\mathrm{S} 2}\right.$ and 

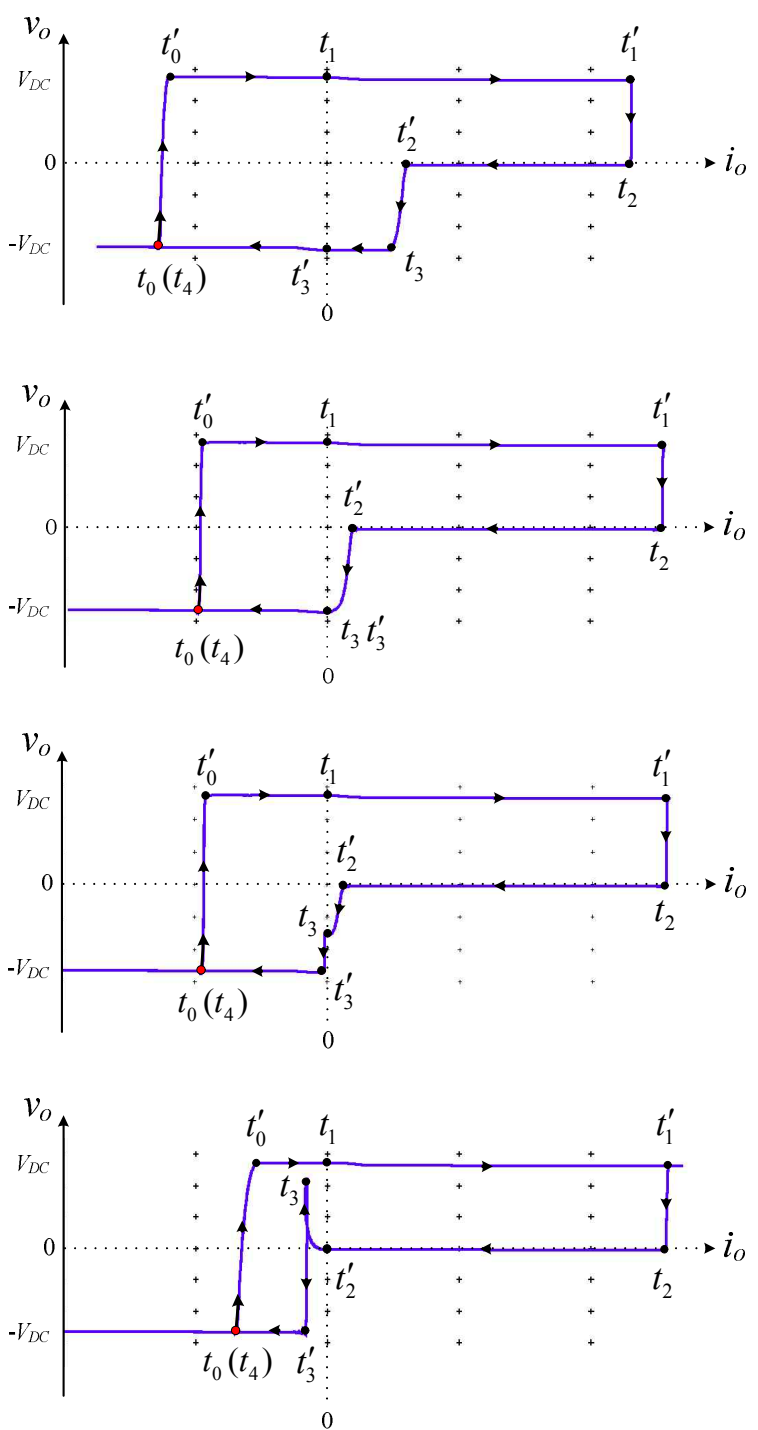

Fig. 7. Phase-plane trajectories of the current and voltage of the inverter and the switch $S_{2}$. (a) Desired ZVS. (b) Critical ZVS. (c) NON-ZVS I. (d) NON-ZVS II.

$v_{\mathrm{S} 2}$ ) for the desired ZVS, critical ZVS, and two NON-ZVS operations are shown in Fig. 7. In Fig. 7(a), the switch current $i_{\mathrm{S} 2}$ is negative while the switch voltage $v_{\mathrm{S} 2}$ decreases from $+V_{\mathrm{DC}}$ to zero at $t_{3}$. The negative current $i_{\mathrm{S} 2}$ flows through the diode $D_{2}$ then reaches zero at $t_{3}^{\prime}$, and ZVS operation is achieved. Under the critical ZVS operation, it can be seen that the switch voltage $v_{\mathrm{S} 2}$, indicated in Fig. 7(b), decreases from $+V_{\mathrm{DC}}$ to zero while the small negative value of the switch current $i_{\mathrm{S} 2}$ also flows through the capacitor $C_{2}$. With an increase in the shifted angle $\beta$ to reduce the output power, the angle $\theta_{i o}$ decreases and becomes less than the angle $\theta_{t d}$. The inverter operates in the NON-ZVS $I$ region as indicated in Fig. 7(c). The negative switch current $i_{\mathrm{S} 2}$ crosses zero and becomes positive while the switch voltage $v_{\mathrm{S} 2}$ is still positive. This causes a current spike in the switch $S_{2}$ during the turn-on transition. Although this current spike is not likely to damage the switch, the inverter's efficiency is sacrificed. Fig. 7(d) (c)

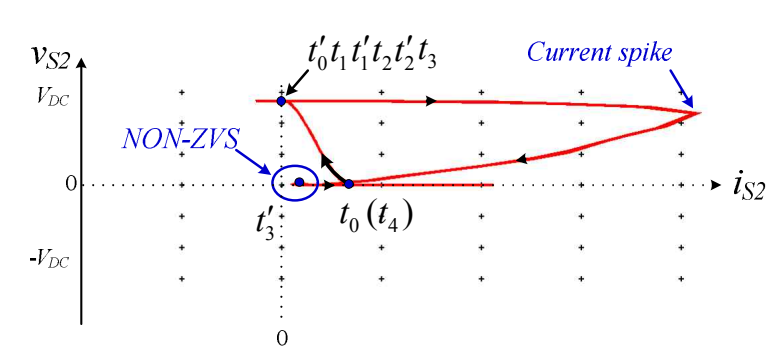

(d)

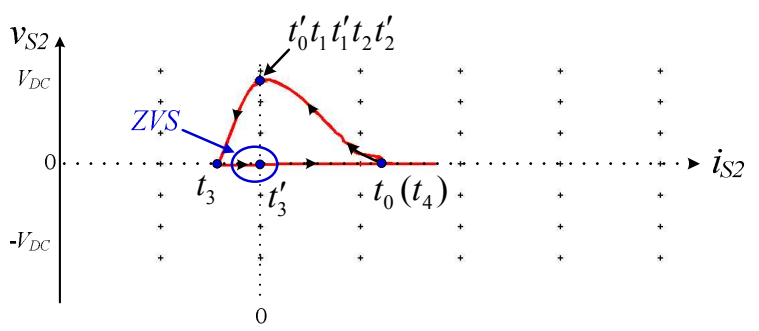

(a)

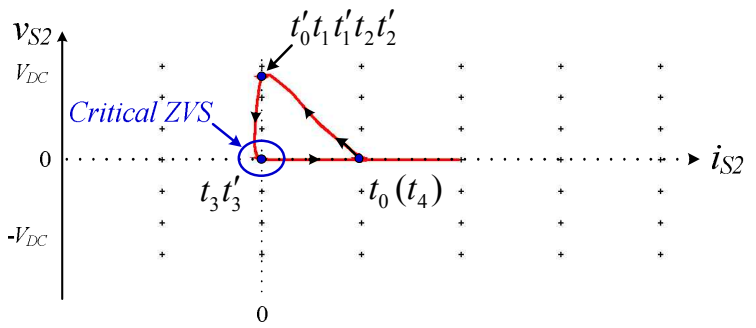

(b)
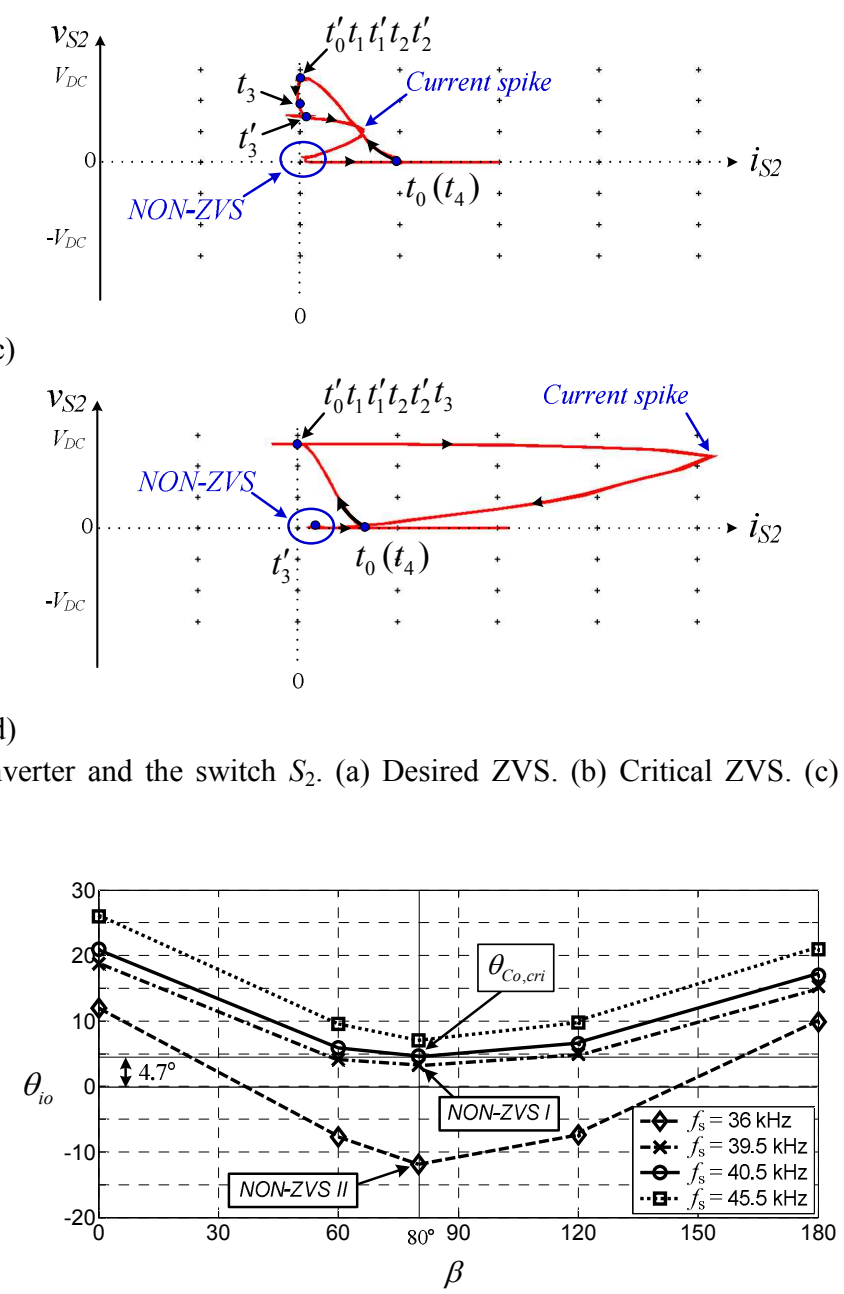

Fig. 8. Relationship between the angle $\theta_{i o}$ and the shifted angle $\beta$ at various switching frequencies $f_{s}$.

shows the phase plane trajectory under the operation of the NON-ZVS II. At $t_{2}^{\prime}$, the output current $i_{o}$ is negative flowing through the diode $D_{1}$, before the switch $S_{1}$ is turned off. The output voltage $v_{o}$ is exposed to the increasing voltage across 


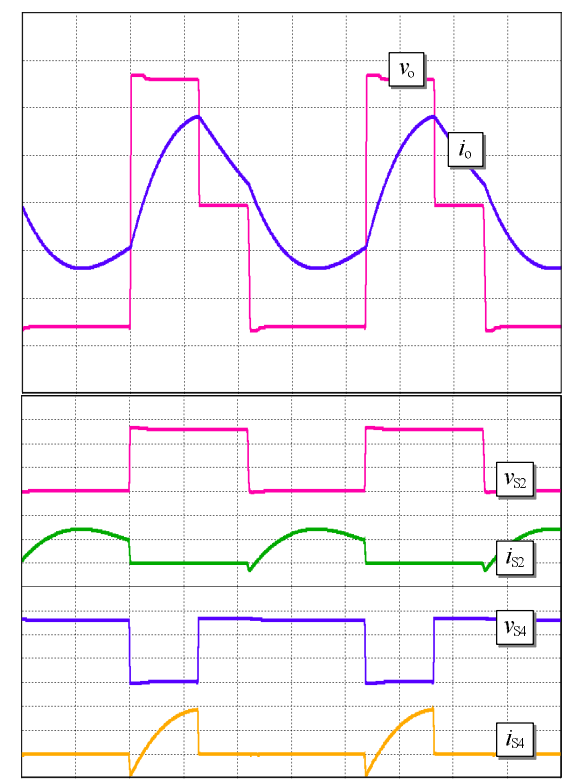

(a)

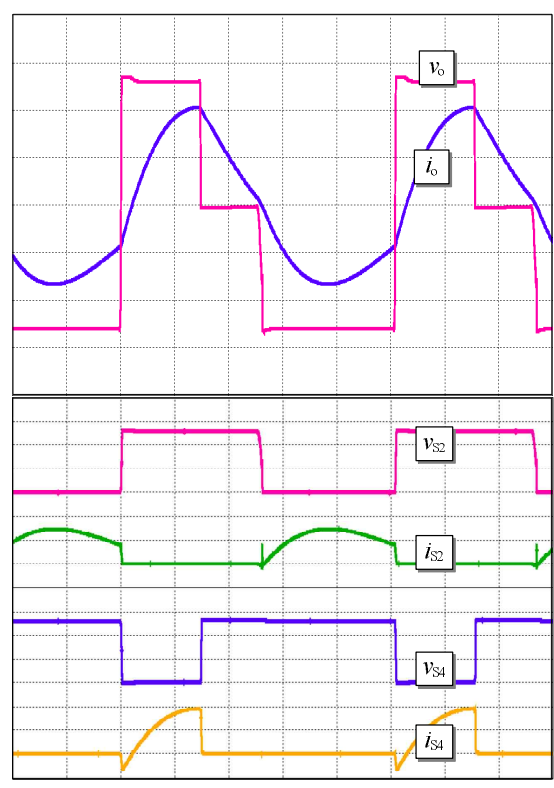

(b)

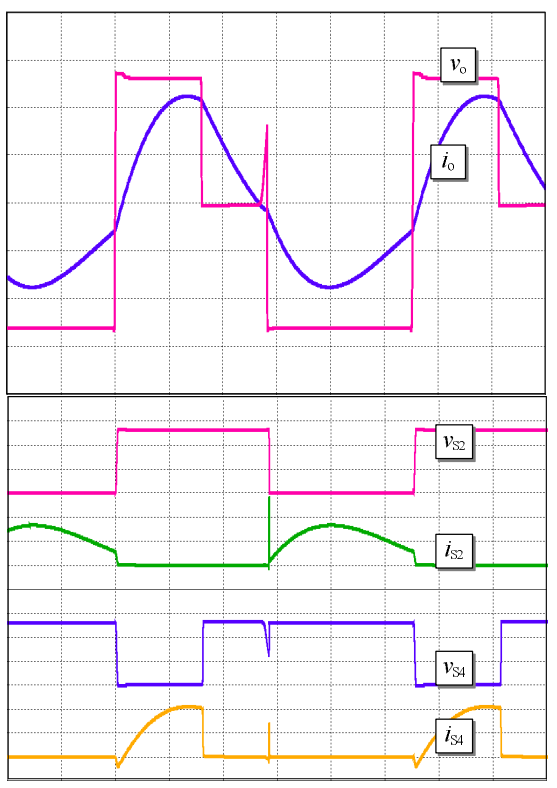

(c)

Fig. 9. Simulation waveforms of $v_{\mathrm{o}}, i_{\mathrm{o}}, v_{\mathrm{S} 2}, i_{\mathrm{S} 2}, v_{\mathrm{S} 4}$ and $i_{\mathrm{S} 4}$ at $\beta=80^{\circ}$ for: (a) Desired ZVS region with $f_{s}=45.5 \mathrm{kHz}$. (b) NON-ZVS $I$ region with $f_{s}=39.5 \mathrm{kHz}$. (c) NON-ZVS $I I$ region with $f_{s}=36 \mathrm{kHz} .\left(v_{\mathrm{o}}: 50 \mathrm{~V} / \mathrm{div}, i_{0}: 5 \mathrm{~A} / \operatorname{div}, v_{\mathrm{S} 2}: 50 \mathrm{~V} / \mathrm{div}, i_{\mathrm{S} 2}: 5 \mathrm{~A} / \operatorname{div}, v_{\mathrm{S} 4}: 50 \mathrm{~V} / \mathrm{div}, i_{\mathrm{S} 4}\right.$ : $5 \mathrm{~A} / \mathrm{div}$ and Time: 5 us/div.).
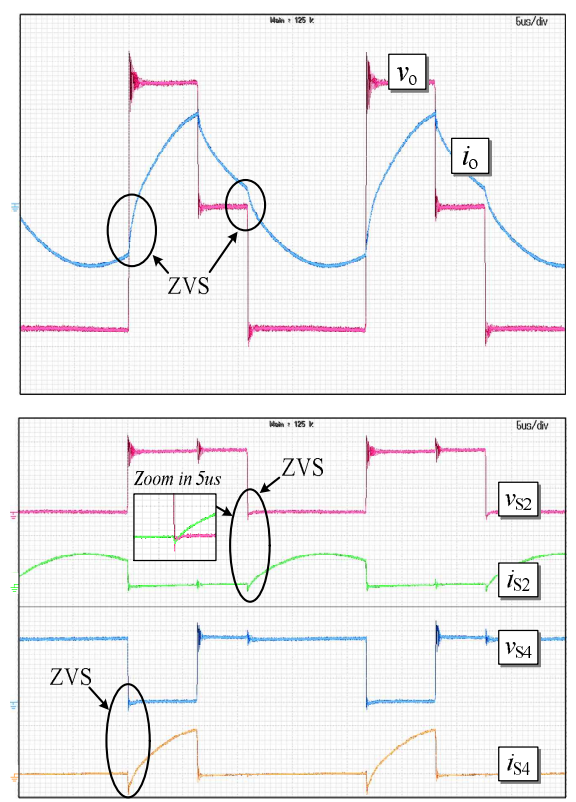

(a)
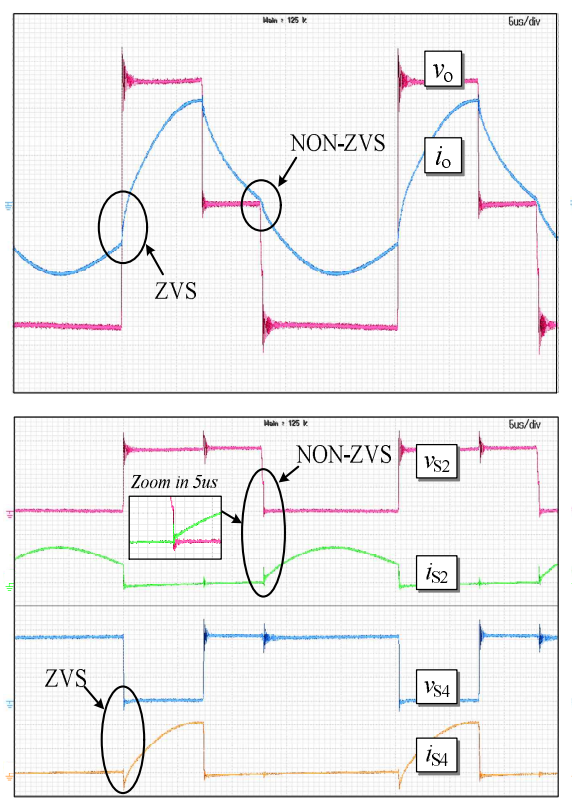

(b)
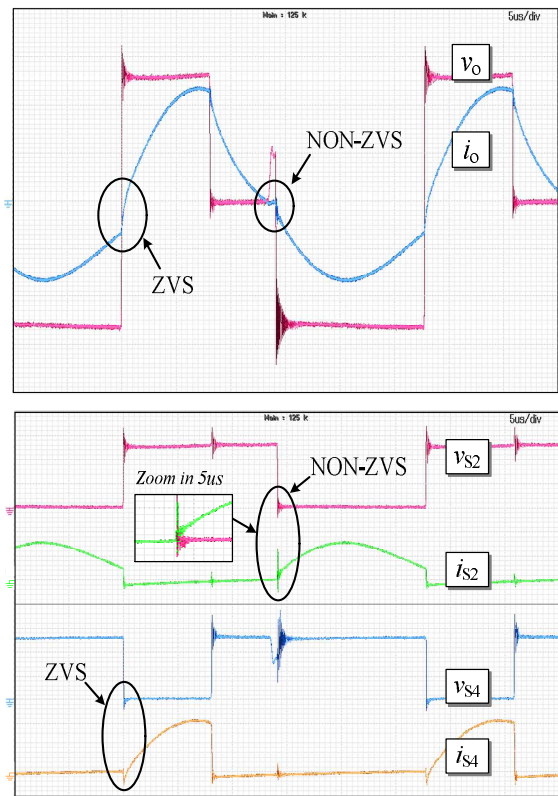

(c)

Fig. 10. Experimental waveforms of $v_{\mathrm{o}}, i_{\mathrm{0}}, v_{\mathrm{S} 2}, i_{\mathrm{S} 2}, v_{\mathrm{S} 4}$ and $i_{\mathrm{S} 4}$ at $\beta=80^{\circ}$ for: (a) Desired ZVS region with $f_{s}=45.5 \mathrm{kHz}$. (b) NON-ZVS $I$ region with $f_{s}=39.5 \mathrm{kHz}$. (c) NON-ZVS II region with $f_{s}=36 \mathrm{kHz}$. $\left(v_{\mathrm{o}}: 50 \mathrm{~V} / \mathrm{div}, i_{\mathrm{0}}: 5 \mathrm{~A} / \mathrm{div}, v_{\mathrm{S} 2}: 50 \mathrm{~V} / \mathrm{div}, i_{\mathrm{S} 2}: 5 \mathrm{~A} / \mathrm{div}, v_{\mathrm{S} 4}: 50 \mathrm{~V} / \mathrm{div}, i_{\mathrm{S} 4}:\right.$ 5A/div and Time: 5us/div.).

the capacitor $C_{3}$, causing a current spike several times the normal current on the switches $S_{2}$ and $S_{3}$. Clearly, the current spike in the NON-ZVS II operation can cause damage to the switches.

The relationship between the angle $\theta_{i o}$ and the shifted angle $\beta$ at various switching frequencies $f_{s}$ is shown in Fig. 8. The output power regulation through the shifted angle $\beta$ has an obvious effect on the angle $\theta_{i o}$. An unsuitable switching frequency can lead to ZVS or NON-ZVS operations. For instance, if the output power is set to the desired value at $\beta=$ $80^{\circ}$. The switching frequency $f_{s}$ at $45.5 \mathrm{kHz}$ yields an operation in the ZVS region because the angle $\theta_{i o}$ is greater than the angle $\theta_{C o, c r i}$ at $4.7^{\circ}$ (where $f_{s}=40.5 \mathrm{kHz}$ ). On the other hand, a switching frequency $f_{s}$ at $39.5 \mathrm{kHz}$ causes the 


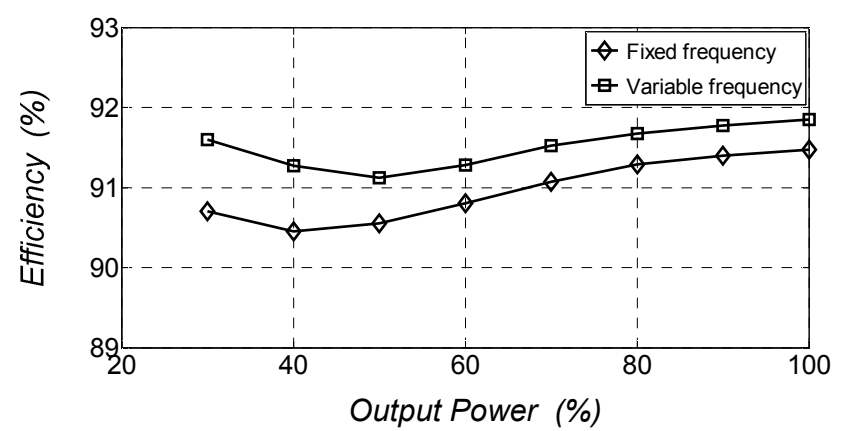

Fig. 11. Efficiency comparison between the variable frequency and the conventional fixed-frequency methods.

angle $\theta_{i o}$ to become less than the angle $\theta_{C o, c r i}$. This is an operation in the NON-ZVS $I$ region. Note that if the angle $\theta_{i o}$ is further decreased, through a switching frequency reduction, the inverter is operated in the NON-ZVS II region. In other words, the angle $\theta_{i o}$ becomes negative as indicated by the dashed line.

The simulation and experimental results under the desired ZVS and two NON-ZVS operations are shown in Figs. 9 and 10. The results under the ZVS operation are shown in Figs. 9(a) and 10(a). The switching frequency of the inverter is then adjusted $(45.5 \mathrm{kHz})$, according to Fig. 6 , where the angle $\theta_{i o}$ becomes $7^{\circ}$ over the angle $\theta_{C o, c r i}$ to assure operation in the desired ZVS region. The results under the operation of the NON-ZVS $I$ are shown in Figs. 9(b) and 10(b) where the angle $\theta_{i o}$ is at $3.2^{\circ}$ to allow for operation in the NON-ZVS $I$ region. In addition, the NON-ZVS II results are shown in Figs. 9(c) and $10(\mathrm{c})$ where the angle $\theta_{i o}$ is $-11^{\circ}$. For the NON-ZVS operations, as observed in the results, the switches $S_{1}$ and $S_{4}$ are turned on at zero voltage, but the switches $S_{2}$ and $S_{3}$ are turned on at non-zero voltage due to the load parameters and unsuitable switching frequency. This results in high switching losses in switches $S_{2}$ and $S_{3}$ which in turn reduces the inverter efficiency. In the case of the NON-ZVS $I I$, the current spikes at the turn-on switching period may cause damages to the switches $S_{2}$ and $S_{3}$.

\section{Efficiency}

An efficiency comparison between the proposed variable frequency and conventional fixed-frequency methods for AVC schemes are provided as shown in Fig. 11. As mentioned earlier, the switching frequency of the fixed-frequency method is set to $45.5 \mathrm{kHz}$ while the switching frequency of the variable frequency method is in the range of $33.75-45.5 \mathrm{kHz}$. Clearly, the variable frequency control yields a higher efficiency, especially in the low output power range, since the switching frequency is allowed to decrease. The benefits of knowing the regions of operation are the insight into the optimal operation as a systematic approach while maintaining the ZVS operation throughout all of the output power levels.

\section{CONCLUSION}

This paper addresses the issue of the regions of ZVS and NON-ZVS operations of a full-bridge inverter focusing on the distorted load current due to a low-quality-factor resonant circuit in induction heating and other applications. The steady-state circuit analysis is based on the asymmetrical control scheme and a Fourier series analysis. The operations of ZVS and NON-ZVS are analyzed in terms of the typical waveform phenomenon of the inverter and the analytical equations in the operation modes. Under the ZVS operating criteria, the parasitic capacitances must also be taken into account. The presented circuit configurations and operations provide insight into the selection of optimal operation with the soft-switching technique to achieve a high efficiency. In addition, this method can be applied to other applications.

\section{REFERENCES}

[1] H. Sugimura, H. Muraoka, T. Ahmed, S. Chandhaket, E. Hiraki, M. Nakaoka, and H. W. Lee, "Dual mode phaseshifted ZVS-PWM series load resonant high-frequency inverter for induction heating super heated steamer," Journal of Power Electronics, Vol. 4, No. 3, pp. 138-151, Jul. 2004.

[2] J. K. Eom, J. G. Kim, J. H. Kim, S. T. Oh, Y. C. Jung, and C. Y. Won, "Analysis of a novel soft switching bidirectional DC-DC converter," Journal of Power Electronics, Vol. 12, No. 6, pp. 859-868, Nov. 2012.

[3] Z. F. Ming and M. C. Zhon, "Impact of zero-voltage notches on output of soft-switching pulse width modulation converters," IEEE Trans. Ind. Electron., Vol. 58, No. 6, pp. 2345-2354, Jun. 2011.

[4] Q. Zhang, H. Hu, D. Zhang, X. Fang, J. Shen, and I. Bartarseh, "A controlled-type ZVS technique without auxiliary components for the low power DC/AC inverter," IEEE Trans. Power Electron., Vol. 28, No. 7, pp. 3287-3296, Jul. 2013.

[5] S. J. Jeon and G. H. Cho, "A zero-voltage and zero-current switching full bridge DC-DC converter with transformer isolation," IEEE Trans. Power Electron., Vol.16, No.5, pp. 573-580, Sep. 2001.

[6] T. Mishima and M. Nakaoka, "A load-power adaptive dual pulse modulated current phasor-controlled ZVS highfrequency resonant inverter for induction heating applications," IEEE Trans. Power Electron., Vol. 29, No. 8, pp. 3864-3880, Aug. 2014.

[7] S. Y. R. Hui, E. S. Gogani, and J. Zhang, "Analysis of a quasi-resonant circuit for soft-switching inverters," IEEE Trans. Power Electron., Vol. 11, No. 1, pp. 106-114, Jan. 1996.

[8] F. Z. Peng, G. J. Su, and L. M. Tolbert, "A passive soft-switching snubber for PWM inverters," IEEE Trans. Power Electron., Vol. 19, No. 2, pp. 363-370, Mar. 2004.

[9] S. S. Lee, S. K. Han, and G. W. Moon, "A new high efficiency half bridge converter with improved ZVS performance," Journal of Power Electron., Vol. 6, No. 3, pp. 187-194, Jul. 2006

[10] E. H. Kim and B. H. Kwon, "Zero-voltage- and zerocurrent-switching full-bridge converter with secondary resonance," IEEE Trans. Ind. Electron., Vol. 57, No. 3, pp. 1017-1025, Mar. 2010.

[11] Y. Kwon, S. B. Yoo, and D. S. Hyun, "Half-bridge series resonant inverter for induction heating applications with 
load-adaptive PFM control strategy," in Proc. APEC, vol. 1, pp.575-581, 1991.

[12] P. Viriya, S. Sittichok, and K. Matsuse, "Analysis of high-frequency induction cooker with variable frequency power control," in Proc. PCC, Vol.3, pp. 1502-1507, 2002.

[13] L. A. Barragan, D. Navarro, J. Acero, I. Urriza, and J. M. Burdio, "FPGA implementation of a switching frequency modulation circuit for EMI reduction in resonant inverter for induction heating applications," IEEE Trans. Ind. Electron., Vol. 55, No. 1, pp. 11-20, Jan. 2008.

[14] H. Fujita and H. Akagi, "Pulse-density-modulated power control of a $4 \mathrm{~kW}, 450 \mathrm{kHz}$ voltage-source inverter for induction melting applications," IEEE Trans. Ind. Applicat., Vol.32, No.2, pp. 279-286, Mar./Apr. 1996.

[15] N. J. Park, D. Y. Lee, and D. S. Hyun, "A power-control scheme with constant switching frequency in class-D inverter for induction-heating jar application," IEEE Trans. Ind. Electron., Vol.54, No.3, pp. 1252-1260, Jun. 2007.

[16] F. Forest, S. Faucher, J. Y. Gaspard, D. Montloup, J. J. Huselstein, and C. Joubert, "Frequency-synchronized resonant converters for the supply of multiwindings coils in induction cooking appliances," IEEE Trans. Ind. Electron., Vol. 54, No. 1, pp. 441-452, Feb. 2007.

[17] O. Lucia, J. M. Burdio, I. Millan, J. Acero, and L. A. Barragan, "Efficiency-oriented design of ZVS half-bridge series resonant inverter with variable frequency duty cycle control," IEEE Trans. Power Electron., Vol. 25, No. 7, pp. 1671-1674, Jul. 2010.

[18] L. Grajales and F.C. Lee, "Control system design and small-signal analysis of a phase-shift controlled series-resonant inverter for induction heating," in Proc. PESC, pp. 450-456, 1995.

[19] P. Viriya, N. Yongyuth, and K. Matsuse, "Analysis of two continuous control regions of conventional phase shift and transition phase shift for induction heating inverter under ZVS and NON-ZVS operation," IEEE Trans. Power Electron., Vol. 23, No. 6, pp. 2794-2805, Nov. 2008.

[20] V. Esteve, J. Jordan, E. S. Kilders, E. J. Dede, E. Maset, J. B. Ejea, and A. Ferreres, "Improving the reliability of series resonant inverter for induction heating applications," IEEE Trans. Ind. Electron., Vol. 61, No. 5, pp. 2564-2572, May. 2014.

[21] J. M. Burdio, L. A. Barragan, F. Monterde, D. Navarro, and J. Acero, "Asymmetrical voltage-cancelation control for full-bridge series resonant inverters," IEEE Trans. Power Electron., Vol. 19, No. 2, pp. 461-469, Mar. 2004.

[22] L. A. Barragan, J. M. Burdio, J. A. Artigas, D. Navarro, J. Acero, and D. Puyal, "Efficiency optimization in ZVS series resonant inverter with asymmetrical voltage-cancelation control," IEEE Trans. Power Electron., Vol. 20, No. 5, pp. 1036-1044, Sep. 2005.

[23] S. Chudjuarjeen, A. Sangswang, and C. Koompai, "An improved LLC resonant inverter for induction heating applications with asymmetrical control," IEEE Trans. Ind. Electron., Vol. 58, No. 7, pp. 2915-2925, Jul. 2011.

[24] J. Jittakort, S. Yachiangkam, A. Sangswang, S. Naetiladdanon, C. Koompai, and S. Chudjuarjeen, "A variable-frequency asymmetrical voltage-cancellation control of series resonant inverter in domestic induction cooking," in Proc. ICPE2011-ECCE Asia, pp. 2320-2327, 2011.

[25] M. K. Kazimierczuk and D. Czarkowski, Resonant Power Converters, John Wiley \& Sons, Chap. 6, 2011.

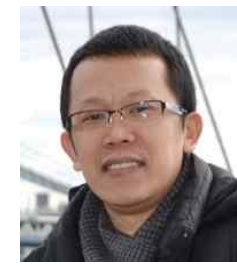

Samart Yachiangkam was born in Lampang, Thailand. He received his B.S. degree in Technical Education from the Rajamangala Institute of Technology (Northern Campus), Chiang Mai, Thailand, in 1997, his B.S. degree in Engineering from the Rajamangala Institute of Technology, Pathum Thani, Thailand, in 2001, and his M.S. degree in Engineering from the King Mongkut's University of Technology Thonburi (KMUTT), Bangkok, Thailand, in 2004. He is presently working toward his Ph.D. in Electrical and Computer Engineering, KMUTT. His current research interests include power electronics and control, and high-frequency soft-switching power converters.

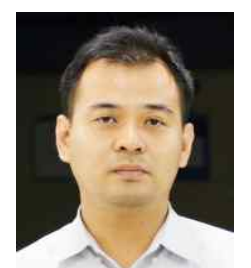

Anawach Sangswang was born in Bangkok, Thailand. He received his B.S. degree in Engineering from the King Mongkut's University of Technology Thonburi (KMUTT), Bangkok, Thailand, in 1995, and his M.S. and Ph.D. degrees from Drexel University, Philadelphia, PA, USA, in 1999 and 2003, respectively. From 1999 to 2003, he was a Research Assistant with the Center for Electric Power Engineering, Drexel University. He is currently an Assistant Professor in the Department of Electrical Engineering, KMUTT. His current research interests include stochastic modeling, the digital control of power electronic converters, and power system stability.

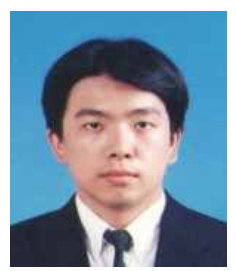

Sumate Naetiladdanon received his B.S. degree in Engineering from Chulalongkorn University, Bangkok, Thailand, in 1995, his M.S. degree from Rensselaer Polytechnic Institute, Troy, NY, USA, in 1999, and his $\mathrm{Ph} . \mathrm{D}$. degree from Osaka University, Osaka, Japan, in 2006. He is presently a Lecturer in the Department of Electrical Engineering, King Mongkut's University of Technology Thonburi (KMUTT), Bangkok, Thailand. His current research interests include power electronics for power quality improvement and renewable energy.

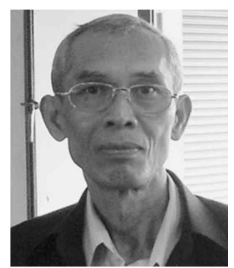

Chayant Koompai was born in Surat Thani, Thailand. He received his B.S. degree in Engineering from the King Mongkut's University of Technology Thonburi (KMUTT), Bangkok, Thailand, in 1973. He has had more than 30 years of experience working in the field of induction heating. His current research interests include circuit analysis and induction-heating systems.

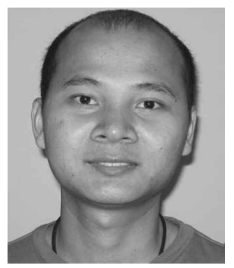

Saichol Chudjuarjeen was born in Prachinburi, Thailand. He received his B.S. degree in Engineering from the Mahanakorn University of Technology, Bangkok, Thailand, in 2000, and his M.S. and Ph.D. degrees in Engineering from the King Mongkut's University of Technology Thonburi (KMUTT), Bangkok, Thailand, in 2004 and 2011, respectively. He is presently a Lecturer with the Department of Electrical and Telecommunication Engineering, Rajamangala University of Technology Krungthep, Bangkok, Thailand. His current research interests include high-frequency resonant inverters for induction heating, current-source and voltage-source inverters, and the control of power-electronic systems. 